\title{
Hemşirelik Birinci Sınıf Öğrencilerinde Kol Maketi Üzerinde Anlatımın Antekübital Bölge Venlerinin Yerlerini Doğru Bulma Başarısı Üzerine Etkisi
}

\section{The Effect of Representation Using an Arm Model on the Finding the Location of Antecubital Area Veins Success of First Year Nursing Students}

\author{
(DAlev Yıldırım Keskin', @Pınar Tunc Tuna', @Birsel Molu', @Halil İbrahim Tuna' \\ 'Selçuk Üniversitesi Akşehir Kadir Yallagöz Sağlık Yüksekokulu, Konya, Türkiye \\ Copyright@Author(s) - Available online at www.dergipark.org.tr/tr/pub/medr \\ Content of this journal is licensed under a Creative Commons Attribution-NonCommercial 4.0 International License.
}

\begin{abstract}
Öz
Amaç: Bu çalışma; öğrencilerin kol maketi üzerinde uygulanan eğitimin antekübital bölge venlerinin yerlerini doğru bulma başarısı üzerine etkisini değerlendirmek amacıyla yapılmıştır.

Materyal ve Metot: Yarı-deneysel nitelikte yapılan bu araştırma, 19 Mart-30 Mart 2018 tarihleri arasında hemşirelik birinci sınıfta okuyan ilk defa Hemşirelik Esasları derini alan 60 öğrenci ile yürütülmüştür. Veriler, literatür doğrultusunda oluşturulan veri toplama formu ile toplanmıştır. Formda yer alan bilgi ve becerilerini değerlendirmeye yönelik sorular ön test ve son test şeklinde uygulanmıştır. Öğrencilerin bilgi ve becerilerini değerlendirme soruları 40 puan, antekübital bölge venlerinin yerlerini doğru tespit etme ise 3 puan üzerinden hesaplanmıştır.

Bulgular. Öğrencilerin kol maketi üzerinde uygulamalı eğitim öncesi ön test puan ortalamaları ile uygulamalı eğitim sonrası son test puan ortalamaları arasındaki fark istatistiksel olarak anlamlı bulunmuştur $(\mathrm{p}<0.05)$. Benzer şekilde antekübital bölge venlerinin yerlerini doğru tespit etme puanları arasındaki fark da istatistiksel olarak anlamlı değerlendirilmiştir $(p<0.05)$.

Sonuç: Öğrencilerin intravenöz kateter uygulamaları hakkındaki bilgi düzeylerini artırmada maket üzerindeki uygulamalı eğitimin etkili olduğu bulunmuştur.
\end{abstract}

\begin{abstract}
Anahtar kelimeler. Hemşirelik öğrencileri; intravenöz kateter uygulaması; simülasyon; uygulamalı eğitim; hasta güvenliği
Abstract

Aim: This study; It was conducted to evaluate the effect of education on the the success of the antecubital region veins on the arm model of the students.

Material and Method: This quasi-experimental study was conducted with 60 students studying in the 1 st year of nursing for the first time, taking the fundamentals of Nursing between 19 March-30 March 2018. The data were collected with a data collection form created in line with the literature. The questions to evaluate the knowledge and skills in the form were applied as pre-test and post-test. The questions to evaluate the students' knowledge and skills were calculated over 40 points, and correctly determining the locations of the antecubital region veins was calculated over 3 points.

Results: The difference between the pre-test mean scores of the students before the applied training on the arm model and the posttest mean scores after the applied training was found to be statistically significant $(p<0.05)$. Similarly, the difference between the scores of correctly locating the antecubital region veins was evaluated statistically significant $(p<0.05)$.

Conclusion: It has been found that practical training on models is effective in increasing students' knowledge about intravenous catheter applications.
\end{abstract}

Keywords: Nursing students; intravenous catheter placement; simulation; practical lecture; patient safety 


\section{GíRiş}

Klinik uygulama sırasındaki temel hedef hata oluşmasını engellemek, hatalar nedeniyle hastayı olası zararlardan korumak ve hata olasılığını ortadan kaldırmaktır $(1,2)$. Hasta güvenliği konuları arasında yer alan ilaç uygulamaları hemşirelerin yasal sorumlulukları arasında bulunmaktadır (3).

İntravenöz uygulamalar, parenteral ilaç uygulamaları arasında sık kullanılan ve etkisi en hızlı olan ilaç uygulamalarıdır (4). Bu uygulamada öncelikle uygulama işlem basamaklarının doğru yapılması gerekmektedir (5). Literatürde intravenöz kateter uygulama bölgesi ve ven doğru seçilmediğinde infiltrasyon, flebit gibi komplikasyonların görüldüğü belirtilmektedir (6-9). Hemşirelik teorik ve klinik eğitiminde bilgi ve beceri düzeyinin geliştirilmesinin infiltrasyon oluşumunu $\% 50$ azalttığı saptanmıştır $(8,10)$.

Öğrencilerin eksik gözetim yapması, simülasyon maketleri ve hasta üzerinde yeterli uygulama yapmaması becerileri öğrenmede ve kendini yeterli hissetmede eksikliklere sebep olmaktadır (11-13). Hemşirelerin klinik beceri yeterliliklerinin geliştirilmesi için Amerikan Hemşirelik Yüksekokulu Birliği simülasyon maketlerinin kullanılmasını önermektedir (14). Jones vd.'nin periferal intravenöz kateterizasyon eğitimi üzerine yaptığı çalışmada, maket kullanmanın birbirleri üzerinde uygulama yapmak kadar etkili olduğu sonucuna ulaşmışlardır (15).

İntravenöz uygulamalardan kaynaklanan komplikasyonlar bilgi ve beceri eksikliği nedeniyle sık görülmektedir. Komplikasyonları önlemeye yönelik olarak hemşirelik öğrencilerinin teorik bilgi ve klinik becerilerinin geliştirilmesi gerektiği vurgulanmaktadır. Bu sebeple bu çalışmanın amacl; hemşirelik birinci sınıf öğrencilerinde kol maketi üzerinde uygulamalı anlatımın bilgi düzeyi ve antekübital bölge venlerinin yerlerini doğru bulma başarısı üzerine etkisini değerlendirmektir.

\section{MATERYAL VE METOT}

Ön test-son test deseninde tasarlanan yarı-deneysel bir araştırmadır. Araştırma, Sağlık Yüksekokulunda 20172018 öğretim yılının güz döneminde, hemşirelik birinci sınıf öğrencileri ile yapılmıştır. Veriler 19 Mart-30 Mart
2018 tarihleri arasında toplanmıştır. Hemşirelik birinci sınıf ögrencilerine kol maketi üzerinde uygulamalı anlatımın antekübital bölge venlerinin yerlerini doğru bulma başarısı üzerine etkisini incelemektir. Araştırmanın evrenini hemşirelik birinci sınıfta okuyan hemşirelik esasları dersini ilk defa alan öğrenciler oluşturmaktadır. Hemşirelik birinci sınıfta toplam 76 öğrenci bulunmaktadır. Araştırmaya katılmayı kabul eden öğrenciler çalışmaya dahil edilmiştir. Araştırmaya klasik ders anlatımında derste bulunan 73 öğrenci, maket üzerinde uygulamalı anlatıma ise; toplam 60 öğrenci katılmıştır. Ön test ve son testin herhangi birine katılmayan 13 öğrenci ve araştırmaya katılmayı kabul etmeyen 3 öğrenci çalışmadan dışlanmıştır. Araştırma 60 öğrenci ile tamamlanmıştır. Evrenin \%78.94'üne ulaşılmıştır. Veriler araştırmacılar tarafından konu ile ilgili literatür taranarak hazırlanan veri toplama formu ile toplanmıştır $(3,4,12,13,15)$. Veri toplama formunun birinci bölümünde, katılımcıların sosyodemografik bilgilerini tanımlamaya yönelik sorular (1-5.sorular), ikinci bölümünde ise; intravenöz uygulamalara ilişkin bilgilerini tanımlamaya yönelik sorular (6-20.sorular) ve 21 . soruda ise öğrencilerden; ön test ve son testte kol maketi şekli üzerinde sefalik, bazilik ve median venin yerlerini işaretlemeleri istenmiştir. Öğrencilerin bilgi ve becerilerini değerlendirmeye yönelik sorular (6-20.sorular) toplam 40 puan üzerinden değerlendirilmiştir. Soru $7,8,9,10,12$, $15,16,17,18,19,20$. sorular birer puan, 6 .soru 10 puan, 11. soru 6 puan, 13. soru 5 puan, 14 . Soru 8 puan olarak hesaplanmıştır. 21. soruda şekil üzerinde gösterilen her doğru vene 1 puan verilerek bu kısım 3 puan üzerinden değerlendirilmiştir. Veri toplama formu öğrencilere iki aşamada uygulanmıştır.

I. Aşamada: uygulamalı anlatım öncesi öntest veri toplama formu öğrencilere dağıtılarak veriler toplanmıştır.

II.Aşamada ise; maket üzerinde uygulamalı anlatım sonrası öğrencilerden son test veri toplama formunu doldurulması istenmiştir. Veri toplama formu öğrencilerin ders ve uygulama bitim saatlerinde uygulanmıştır. Verileri toplama süresi her bir öğrenci için yaklaşık 5-10 dk sürmüştür. Veri karışıklığını önlemek için her öğrenciden öncesi ve sonrası testte aynı numarayı vermesi istenmiştir. Şekil 1'de örneklem diyagramı ile açıklanmıştır.

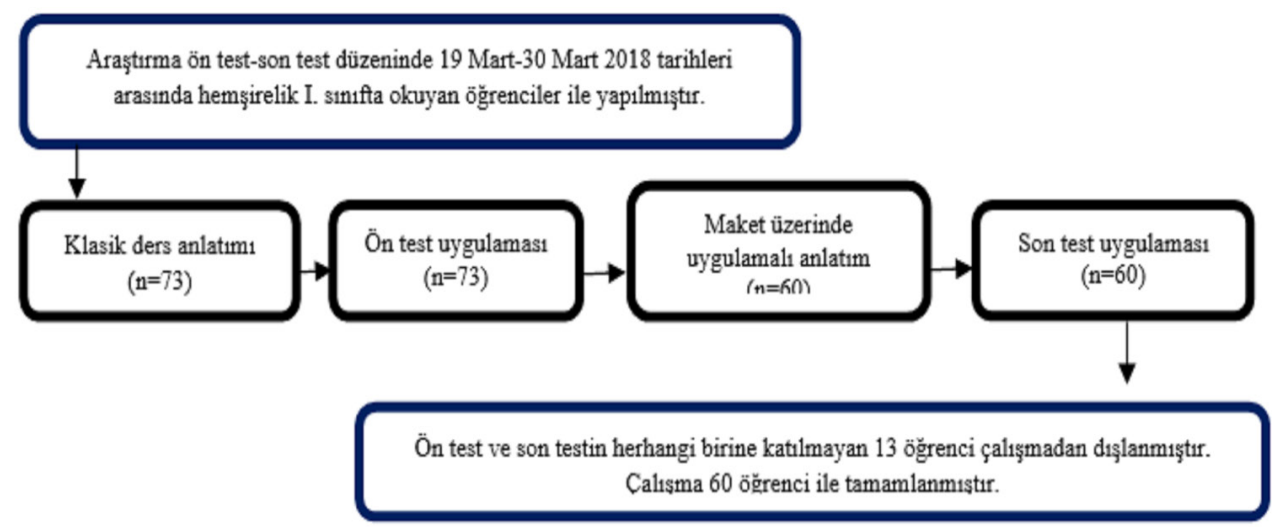

Figür 1. Örneklem Diyagramı 
Araştırmanın yapılabilmesi amacı ile Selçuk Üniversitesinin Yüksekokulu'ndan (85336622-108.99/ sayılı), Selçuk Üniversitesinin Girişimsel Olmayan Etik Kuruldan (050.01.04, 2018/136 sayılı karar) ve araştırmaya katılmayı kabul eden öğrencilerden yazılı izler alınmıştır. Bu çalışma, Dünya Tıp Birliği (WMA) HELSINKI Bildirgesi (ve/veya Dünya Psikiyatri Birliği HAWAll Bildirgesi İyi Klinik Uygulamaları gözetilerek yapılmıştır.

Verilerin değerlendirilmesinde SPSS 24.0 programı kullanılmıştır. Veri toplama formunda öğrencilerin sosyodemografik bilgilerini içeren ilk 1-5. sorudan elde edilen veriler sayı, yüzdelik, minumum-maksimum puanlar ve standart sapma olarak değerlendirilmiştir. Öğrencilerin uygulamalı eğitim öncesi ve sonrası bilgi puanlarının karşılaştırılmasında ise; Pared Sample t Testi kullanılmıştır.

Bu çalışma ülkemizde hemşirelik birinci sınıf öğrencilerinin genelini yansıtmamakta olup çalışmanın yapıldığı yüksekokulda öğrenim gören ve Hemşirelik Esasları dersini alan öğrenciler ile sınırlıdır.

\section{BULGULAR}

ablo 1'de araştırmaya katılan öğrencilerin \%80'i 18-19 yaş aralığında, \%76.6'ı kadın, \%56.7'i Anadolu Lisesi mezunu, \%66.7'i bölümü isteyerek seçtiği ve \%83.3'ünün bölümü seçmekten memnun olduğunu saptanmıştır (Tablo 1).

Tablo 2'de öğrencilerin maket üzerinde uygulamalı eğitim öncesi ve sonrası intravenöz uygulamalara ilişkin sorulardan aldıkları puanların ortalamaları arasında anlamlı fark olduğu belirlenmiştir $(t=5.18, p=0.000)$.

Tablo 3'te öğrencilerin maket üzerinde uygulamalı eğitim öncesi ve sonrası antekübital bölge venlerinin yerlerini bilme durumları arasında anlamlı fark olduğu tespit edilmiştir $(t=7.82, p=0.000)$.

Tablo 1. Araştırmaya katılan öğrencilerin tanıtıcı bilgilerinin dağıııı

Tanıtıcı Bilgiler $(n=60)$

Yaş

18-19 yaş

20-21 yaş

Cinsiyet

Kadın

Erkek

Mezun olunan lise

Sağlık meslek lisesi

10

34

16

Diğer liseler

Bölümü isteyerek seçme durumu

Evet

40

20

Hayır

Bölümü okumaktan memnun olma durumu

Evet

50

10
Yüzde (\%)

80.0

20.0

76.6

23.4

16.7

56.7

26.6

66.7

33.3

83.3

16.7

Tablo 2. Maket üzerinde uygulamalı eğitim öncesi ve sonrası ön test ve son test puan ortalamalarının karşılaştırılması

$\begin{array}{lcccc}\text { Değişken } & \text { X } & \text { Standart Sapma (SS) } & \text { Min } & \text { Max } \\ \text { Uygulamalı Eğitim Öncesi Ön Test Puan Ortalamaları } & 25.96 & 5.46 & 24.50 & 27.33 \\ \text { Uygulamalı Eğitim Sonrası Son Test Puan Ortalamaları } & 30.35 & 5.32 & 28.96 & 31.70\end{array}$

* Eşleştirilmiş örneklemler için Paired Sample t testi (Normal dağılım gösteren iki bağımlı grubun eğitim öncesi ve sonrası toplam puan ortalamalarının karşılaştırılması) 
Tablo 3. Maket üzerinde uygulamalı eğitim öncesi ve sonrası antekübital bölge venlerinin yerini doğru bilme puan ortalamalarının karşılaştırılması

\begin{tabular}{|c|c|c|c|c|c|c|}
\hline Değişken & $\mathbf{X}$ & Standart Sapma (SS) & Min & Max & $\mathbf{t}$ & p* \\
\hline Uygulamalı Eğitim Öncesi Antekübital Bölge Venlerinin Yerini Bilme & 1.13 & 1.18 & 0.50 & 1.13 & & \\
\hline
\end{tabular}

* Eşleştirilmiş örneklemler için Paired Sample t testi (Normal dağılım gösteren iki bağımlı grubun eğitim öncesi ve sonrası toplam puan ortalamalarının karşılaştırılması)

\section{TARTIŞMA}

Literatür incelendiğinde; simülasyon maketleri üzerinde uygulamalı eğitimin öğrencilerde deneyime dayalı kalıcı öğrenme sağladığı, hastaya zarar verme kaygısını azalttığı, kendilerine olan güveni artırdığı, klinik karar verme becerilerini geliştirdiği, başarı ve motivasyon düzeylerini artırdığı belirtilmektedir (16-19).

Çalışmamızda; kol maketi üzerinde uygulamalı eğitimin ön test ve son test puan ortalamaları ve antekübital bölge venlerinin yerleri bulmaya ilişkin puanlar arasında anlamlı bir fark olduğu saptanmıştır $(p<0.05)$ (Tablo 2 ve Tablo 3 ). Kol maketi üzerinde uygulamalı anlatım sonrası son test puan ortalamalarının ön test puan ortalamalarına göre yüksek çıkması simülasyon maket üzerindeki uygulamalı eğitimin bilgi ve beceriyi artırdığı söylenebilir.

Liaw vd. (2010)'nın çalışmasında Singapur'da birinci sınıf hemşirelik öğrencilerinde simülasyon temelli öğrenme aktivitesine katılan 30 öğrencinin ön testten 20.8 puan, son testten 27.56 puan almışlardır. Simülasyon temelli öğrenmenin kriz yönteminde ve değerlendirmesinde etkili bir eğitim stratejisi olduğunu sonucuna ulaşmışlardır (20). Liaw vd. (2012)'nın yaptığı başka bir çalışmada ise, simülasyon ile eğitim yaptırdıkları öğrencilerin kontrol grubu öğrencilerine göre bilgi ve becerilerinin daha fazla olduğunu saptanmıştır (18). Çayır ve Özkal (2017)'nın hemşirelik bakımı öğretiminde simülasyonun öğrenci başarısı üzerine etkisini değerlendikleri çalışmalarında; öğrencilerin simülasyon eğitimi sonrası başarı puanlarının simülasyon eğitimi öncesi başarı puanlarından daha yüksek olduğunu bulmuşlardır (21). Çalışma sonucumuz simülasyonla eğitimin etkili olduğu çalışmalarla benzerlik göstermektedir. Bu çalışma sonuçlarından hareketle; öğrencilerin bilgi ve becerilerini artırmak için maketler üzerinde uygulamalı anlatımın klinik uygulamalar üzerinde olumlu etki yaptığı söylenebilir.

Çalışmamızda; uygulamalı eğitim sonrası öğrencilerin \%96.6 $(n=58)$ testten geçer puan aldığı tespit edilmiştir. Simülasyonla eğitimde öğrencilerin uygulamada daha başarılı olduğu saptanmıştır. Yapılan çalışmalar incelendiğinde; Chang vd. (2002)'nın geleneksel yöntem ve kol maketi üzerinde intravenöz kanül yerleştirmeyi karşılaştırdıkları çalışmalarında; hem kol maketi hem de geleneksel yöntem kullanımında yüksek başarı elde ettikleri görülmektedir (22). Shepherd vd. (2010)'nın öğretim stratejisi olarak simülasyon eğitiminin öğrencilerin hemşirelik becerileri üzerinde uygulama alanlarında etkili olduğunu bulmuşlardır (23). Ricketts (2011)'in çalışmasında, simülasyonlu eğitimin klinik becerilerini arttırdığını vurgulamaktadır (16). Jones vd. (2014)'nın periferal intravenöz kateterizasyon eğitimi üzerine yaptığı çalışmada, maket üzerinde uygulamalı eğitimde öğrencilerin uygulamada daha başarılı olduğunu saptamışlardır (15). Gürol vd. (2016)'nın simulasyon uygulamalarının öğrencilerin beceri seviyelerine etkisini ölçmek için yaptıkları çalışmada, simülasyonla eğitimin öğrencilerin beceri düzeylerini artırdığını belirtmişlerdir (17). Zarifsanaiey vd. (2016)'nın hemşirelik ilkeleri dersinde kullanılan simülasyonla eğitimin öğrencilerin performans düzey ortalama puanlarını ve uygulama becerilerini artırdığını saptamışlardır (24). Arslan vd. (2018)'nın çocuk hemşireliği öğrencilerinde geleneksel yöntem ve simülasyona dayalı eğitimi karşılaştırdıkları çalışmada; simülasyon temelli hemşirelik eğitiminin, uygulama becerilerini artırdığı saptanmıştır (25). Çalışma bulgularımız literatür bulgularını destekler nitelikte olup hemşirelik esasları dersindeki maket üzerinde uygulamalı anlatımın; öğrencilerin bilgi puanlarını artırdığı ve uygulama becerilerini geliştirdiğini düşündürmektedir.

\section{SONUÇ}

Bu çalışmada hemşirelik birinci sınıf öğrencilerinde simülasyon kol maketi ile verilen eğitimin klasik ders anlatımına göre bilgilerini artırdığı, öğrencilerin hem teorik hem de uygulamalı eğitimi bir arada almanın bilgi ve becerilerini artırmada daha etkili olduğu sonucuna ulaşılmıştır. Kol maketi üzerinde uygulamalı anlatım sonrası öğrencilerin bilgi puanlarının ve becerilerinin arttığı tespit edilmiştir. Maket üzerindeki eğitimin öğrenci memnuniyeti üzerinde olumlu etkisi bulunmuştur. Sonuç olarak; maket üzerindeki uygulamalı eğitimin öğrenci memnuniyetini ve öğrencilerin uygulamadaki başarısını artırdığı göz önünde bulundurulduğunda uygulamalı eğitimin hasta memnuniyetini ve kaliteyi artıracağı düşünülmektedir.

$\mathrm{Bu}$ sonuçlar doğrultusunda önerimiz, hasta güvenliği açısından klinik uygulama öncesi klasik ders anlatımına paralel olarak simülasyon maket eğitimlerinin artırılması olacaktır. Gelecek çalışmaların gelişmiş simülasyon maketleri üzerinde daha fazla sayıda öğrenci ile farklı sınıf düzeylerinde de yapılması hemşirelik eğitimine katkı 
sağlayacağı düşünülmektedir.

Finansal destek: Çalışmayı maddi olarak destekleyen kişi/kuruluş yoktur.

Çıkar Çatışması: Yazarlar arasında herhangi bir çıkar çatışması yoktur.

Etik onay: Konya Selçuk Üniversitesi, No: 2018/36

\section{REFERENCES}

1. Gökdoğan F, Yorgun S. Sağlık hizmetlerinde hasta güvenliği ve hemşireler. Anadolu Hemşirelik ve Sağlık Bilimleri Dergisi 2010;13:53-9.

2. Sur H, Özsarı H, Say B. Hasta Güvenlği. Sur H, Palteki, T (Editörler). Hastane Yönetimi, Nobel Tıp Kitabevleri: İstanbul; 2013. p. 509-19.

3. Çetinkaya Uslusoy E, Duran ET, Korkmaz M. Güvenli enjeksiyon uygulamaları, Hacettepe Üniversitesi Hemşirelik Fakültesi Dergisi 2016;3:50-7.

4. Karabacak BG. Parenteral ilaç uygulamaları. In: Sabuncu N, Ay FA (Editörler), Klinik beceriler Sağlığın değerlendirilmesi ve hasta bakımı. Nobel Tıp Kitapevler 2010;251-5.

5. Akça Ay F. Sağlık uygulamalarında temel kavramlar ve beceri kitabı, Nobel Tıp Kitabevi 2015;473-559.

6. Phillips DL, Gorski L. Manual of I.V. Therapeutics, evidencebased practice for infusion therapy. 6 th ed. Philadelphia: F.A. Davis Company 2014;545-61.

7. Saini R, Agnihotri M, Gupta A, Walia I. Epidemiology of infiltration and phlebitis, Nursing \& Midwifery J 2011;7:2233.

8. Jacinto L, Karina A, Machado AH, et al. Predisposing factors for infiltration in children submitted to peripheral venous catheterization, J Infus Nurs 2011;34:391-8.

9. Lazarus HM, Trehan S, Miller R, Fox RM, Creger RJ, Raaf JH. Multipurpose silastic dual-lumen central venous catheters for both collection and transplantation of hematopoietic progenitor cells, Bone Marrow Transplant 2000;25:779-85.

10. Woody G, Davis BA. Increasing nurse competence in peripheral intravenous therapy, J Infus Nurs 2013;36:413-9.

11. Akyüz A. Hemşirelik beceri eğitiminde yenilikçi uygulamalar. Sağlık bilimlerinde klinik ve iletişim beceri eğitimleri kongresi. Kongre ÖÖet kitabı. Ankara, 2011;30-73.

12. Oktay BH. Hemşirelik becerileri eğitiminin değerlendirilmesi, sağlık bilimlerinde klinik ve iletişim beceri eğitimleri kongresi, Ankara, kongre Özet Kitabı 2011;20-56.

13. Medley C, Horne C. Using simulation technology for undergraduate nursing education, J Nurs Edu. 2005; 44:314.
14. Anderson C, Powell D. Faculty shortages in baccalaureate and graduate nursing programs: Scope of the problems and strategies for expanding the supply (issue bulletin), Washington, DC: American Association of Colleges of Nursing 2005, pp 19-42. https://www.aacnnursing.org/ Portals/42/News/White-Papers/facultyshortage-2005.pdf. Erişim Tarihi 01.03.2019.

15. Jones RS, Simmons A, Boykin Sr GL, et al. Measuring Intravenous cannulation skills of practical nursing students using rubber mannequin Intravenous training arms, Military Med 2014;179:1361-7.

16. Ricketts $B$. The role of simulation for learning within preregistration nursing education a literature review, Nurse Educ Today 2011;31:650-54.

17. Gürol A, Akpınar R, Apay S. Effect of simulation applications on students' skill levels, Kocatepe Med J 2016;17:99-104.

18. Liaw SY, Scherphier A, Rethans JJ, et al. Assessment for simulation learning outcomes: A comparison of knowledge and self-reported confidence with observed clinical performance, Nurse Educ Today 2012;32:35-9.

19. Warren JN, Luctkar Flude M, Godfrey C, et al. Asystematic review of the effectiveness of simulation-based education on satisfaction and learning outcomes in Nurse Practitioner Programs, Nurse Educ Today 2016;46:99-108.

20. Liaw SY, Chen FG, Klainin P, et al. Developing clinical competency in crisis event management: An integrated simulation problem-based learning activity, Adv Health Sci Education 2010;15:403-13.

21. Çayır A, Özkal F. The The use of simulation in nursing education: The example of myocardial infarction. Research on Education and Psyshology 2017;1:38-46.

22. Chang KK, Chung JW, Wong TK. Learning intravenous cannulation: A comparison of the conventional method and the cathsim intravenous training system. J Clin Nurs 2002;11:73-8.

23. Shepherd CK, McCunnis M, Brown L, et al. Investigating the use of simulation as a teaching strategy, Nurs. Stand 2010;24:42-8.

24. Zarifsanaiey N, Amini M, Saadat FA. Comparison of educational strategies for the acquisition of nursing student's performance and critical thinking: Simulationbased training vs. integrated training (simulation and critical thinking strategies), BMC 2016;16:294-1-7.

25. Arslan Taş F, Türkmen Sonay A, Çelen $R$, et al. Comparing traditional and simulation-based experiences in pediatrics with undergraduate nursing students in Turkey, Clin Simul Nurs 2018;16:62-9. 